\section{Can Common Lead Apron in Testes Region Cause Radiation Dose Reduction during Chest CT Scan? A Patient Study}

\author{
Mohammad Kiapour ${ }^{1 \odot}$, Kourosh Ebrahimnejad Gorji², Rahele \\ Mehraeen ${ }^{3}$, Naser Ghaemian4, Fatemeh Niksirat Sustani5, \\ Razzagh Abedi-Firouzjah5, Ali Shabestani Monfared ${ }^{6 *(0)}$
}

\begin{abstract}
Background: Computed tomography $(\mathrm{CT})$ is a routine procedure for diagnosing using ionization radiation which has hazardous effects especially on sensitive organs.

Objective: The aim of this study was to quantify the dose reduction effect of lead apron shielding on the testicular region during routine chest CT scans.

Material and Methods: In this measurement study, the routine chest CT examinations were performed for 30 male patients with common lead aprons folded and positioned in testis regions. The patient's mean body mass index (BMI) was $26.2 \pm$ $4.6 \mathrm{~kg} / \mathrm{m}^{2}$. To calculate the doses at testis region, three thermoluminescent dosimeters (TLD-100) were attached at the top surface of the apron as an indicator of the doses without shielding, and three TLDs under the apron for doses with shielding. The TLD readouts were compared using SPSS software (Wilcoxon test) version 16.
\end{abstract}

Results: The radiation dose in the testicular regions was reduced from $0.46 \pm$ 0.04 to $0.20 \pm 0.04 \mathrm{mGy}$ in the presence of lead apron shielding $(\mathrm{p}<0.001)$, the reduction was equal to $56 \%$. Furthermore, the heritable risk probability was obtained at $2.0 \times 10^{-5} \%$ and $4.6 \times 10^{-5} \%$ for the patients using the lead apron shield versus without shield, respectively.

Conclusion: Applying common lead aprons as shielding in the testis regions of male patients undergoing chest $\mathrm{CT}$ scans can reduce the radiation doses significantly. Therefore, this shield can be recommended for routine chest CT examinations.

Citation: Kiapour M, Ebrahimnejad Gorji K, Mehraeen R, Ghaemian N, Niksirat Sustani F, Abedi-Firouzjah R, Shabestani Monfared A. Can Common Lead Apron in Testes Region Cause Radiation Dose Reduction during Chest CT Scan? A Patient Study. J Biomed Phys Eng. 2021;11(4):497504. doi: 10.31661/jbpe.v0i0.2104-1307.

\section{Keywords}

Computed Tomography; Radiation Protection; Chest CT Scan; Lead Apron; Testis; Thermoluminescent Dosimetry

\section{Introduction}

omputed tomography (CT) using ionizing radiation, is widely
used as an appropriate choice for the diagnosis of many diseases
[1], and is known as one of the main contributors to the collective effective dose and also accounts for approximately $68 \%$ of the total medical radiation exposure in the world [2].

Although in CT procedures, the collective effective dose is higher compared to other modalities such as common radiographies, the number of CT examinations is continually increasing [2-4] at an annual rate of 10 percent in the U. S. [5] due to the higher diagnostic value of CT images. Since ionization radiation can cause genetic side effects or carci-
${ }^{1} \mathrm{MSc}$, Student Research Committee, Babol

University of Medical Sci-

ences, Babol, Iran

${ }^{2} \mathrm{PhD}$, Department of

Medical Physics Radio-

biology and Radiation

Protection, School of

Medicine, Babol Univer-

sity of Medical Sciences,

Babol, Iran

${ }^{3} \mathrm{MD}$, Department of

Pediatric Radiology,

Babol University of Medi-

cal Sciences, Babol, Iran

${ }^{4} \mathrm{MD}$, Department of

Radiology and Ra-

diotherapy, School of

Medicine, Babol Univer-

sity of Medical Sciences,

Babol, Iran

${ }^{5} \mathrm{MSc}$, Department of

Medical Physics Radio-

biology and Radiation

Protection, School of

Medicine, Babol Univer-

sity of Medical Sciences,

Babol, Iran

${ }^{6} \mathrm{PhD}$, Cancer Research

Center, Health Research

Institute, Babol Univer-

sity of Medical Sciences,

Babol, Iran

*Corresponding author:

Ali Shabestani Monfared

Cancer Research Center,

Health Research Insti-

tute, Babol University

of Medical Sciences,

Babol, Iran

E-mail: monfared1345@ gmail.com

Received: 14 April 2021 Accepted: 31 May 2021 
nogenesis which may appear in the newborns [6], concern about it has increased [7,8]. In addition, with the introduction of multi-detector CT (MDCT) for the clinical applications, a further increase in the overall number of CTs has been reported [7].

CT scan from the chest is a primary diagnostic tool for common examination for diagnosing the diseases of the lung and other organs located in the chest region [9]. Protecting the organs especially sensitive ones from radiation damage during $\mathrm{CT}$ examinations is crucial [10]. Testes are one of the radiosensitive organs and regarding the International Commission on Radiation Protection (ICRP) reports, the weighting factor of this organ is higher than other sensitive organs, which is equal to 0.2 [11], and it contributes $20 \%$ of the effective whole-body dose [12].Therefore, any methods which can reduce the dose without affecting the diagnostic image quality should be performed.

The patient's dose in CT procedures consists of primary X-ray beam and scatter components; therefore, radiation shielding is a challenging issue [13]. Reducing the sensitive organs' doses by appropriate easy applicable shields can be helpful in this regard $[4,14]$. There are various shields designed to reduce gonadal doses, including lead blankets, clamshell style shields, bismuth shielding, male testicular shields, and flexible shields [14]. However, these shields are not widely used in routine $\mathrm{CT}$ examinations due to their hard placement, lack of hygienic tips, and accessibility.

In several studies, the testes' shielding effects during CT scans have been investigated. For example, Iball et al. [10] assessed abdominal lead shielding on the gonad doses during the chest CT examination using RANDO phantom and TLDs. In another study [15], the authors estimated the gonads' doses by an ion chamber in the presence of surface lead shield in RANDO anthropomorphic phantom during different CT scan examinations.
The previous studies were conducted on phantoms $[10,14]$ or a particular testicular shield which is hard to use $[12,16]$. However, in the present study, we investigated the dose reduction effect of lead apron in the testicular region during chest MDCT procedures. The advantage of our method is that the shielding instrument namely lead apron, positioned on the patients' testis regions, is accessible in all CT centers.

\section{Material and Methods}

In this measurement study, for the purpose of measuring the testes surface dose during the chest CT scan, 30 patients were involved in the presence of lead apron folded and positioned on the Patients' testis regions. A MDCT scanner (16 slice Somatom Emotion 16, Siemens, Germany) was used for scanning, and radiation dose values were measured using thermoluminescent dosimeter (TLD) chips.

\section{Patients groups}

Thirty male patients with age ranging from 20 to 70 years old and the mean body mass index (BMI) of $26.2 \pm 4.6 \mathrm{~kg} / \mathrm{m}^{2}$ (median 26) were chosen for this study. The patients were informed and satisfied about how the procedure would be performed. The study was carried out following the National Research Ethics Board approval with the registration number of "IR.MUBABOL.HRL.REC.1398.194".

The patients with special problems, including solitary testes, scrotal masses, scrotal skin infections, or lesions were excluded in this study. Although gonad protection is more important in the pediatric groups, this age group was not investigated because of the difficulty of obtaining children's parental approval.

\section{Scan protocol}

The parameters of the chest CT scanning protocols with a MDCT scanner are indicated in Table 1. All scans were without any contrast material and the scan range was from lung apices to lung bases, which yielded the mean 
Table 1: Computed tomography (CT) scan parameters used for chest examination for all participants

\begin{tabular}{cc} 
Parameter & Value \\
\hline Tube voltage $(\mathrm{kVp})$ & 130 \\
\hline Effective tube current-time product (mAs) & 80 \\
\hline Rotation time (s) & 1 \\
\hline Image slice thickness (mm) & 5 \\
\hline Pitch & 1 \\
\hline CT dose index (CTDI $\left.{ }_{\text {vol' }} \mathrm{mGy}\right)$ & $5.6 \pm 1.5$ \\
\hline Dose length product (DLP, $\mathrm{mGy} . \mathrm{cm})$ & $192 \pm 30$ \\
\hline Total scan time (s) & $9.5 \pm 1.1$ \\
\hline Scan field of view & Large
\end{tabular}

CT: Computed tomography, CTD: Computed tomography dose index, DLP: Dose length product

scan length of $33 \pm 2.1 \mathrm{~cm}$. The patients were placed in supine position.

\section{TLD dosimetry}

TLD chips are produced by Harshaw Company (Thermo Electron Corporation, Reading, UK) and made of $\mathrm{LiF}, \mathrm{Mg}$ and $\mathrm{Ti}$ with the thickness of $0.9 \mathrm{~mm}$ and size of $3 \times 3 \mathrm{~mm}^{2}$. All TLDs were annealed in a TLD annealing furnace $\left(1 \mathrm{~h}\right.$ at $400{ }^{\circ} \mathrm{C}$ and $2 \mathrm{~h}$ at $\left.100^{\circ} \mathrm{C}\right)$ before the measurements, and also prior to the readout, the dosimeters were pre-heated at $100^{\circ} \mathrm{C}$ for 20 minutes (min). The TLDs were exposed using an $80 \mathrm{kVp}$ diagnostic X-ray beam, resulting in the use of a sensitivity correction, in a way that, the TLDs which were over or under sensitive by greater than 2 standard deviations were eliminated.

The TLD chips' calibration was done based on Groves et al. [17] study. In summary, the Element Correction Coefficient (ECC) values were obtained to increase the reproducibility for each TLD. Moreover, a Barracuda dosimeter (RTI Electronics, Sweden) calibrated at the Secondary Standard Dosimetry Laboratory (SSDL) was used for the verification of the dose measurement. The TLDs were irradiated three times in free-in-air conditions at the cen- ter of rotation of the CT scanner, and the mean readout values of the TLDs (TLD mean) were obtained. The ECC for each TLD (TLD ${ }_{\mathrm{i}}$ ) was calculated using the following Equation 1:

$$
E C C_{i}=T L D_{i} / T L D_{\text {mean }}
$$

In the next step, to obtain the calibration factor (CF), the TLDs (ECC close to 1) were exposed three times to different selected doses, and the average of TLD readouts was calculated. Then the dose (mGy) versus TLD reading (nC) was plotted, and the $\mathrm{CF}$ was obtained by the slope of the curve. It is notable that the readout and analysis of the TLDs were performed at the National Medical Physics Research Center after $24 \mathrm{~h}$, which has a special protocol for TLD analysis. Furthermore, a pair of TLD chips was located in the CT room far from the source of radiation $(>3 \mathrm{~m}$ ) for measuring the background dose for each patient. The uncertainty for the determined dose of TLDs was estimated from the standard error of repeated measurements and obtained at \pm $2 \%$. Finally, the surface dose for the organ was obtained by multiplying the mean values of the TLD readouts, ECC, and CF values.

\section{TLDs location on the lead apron}

Two lead aprons with a thickness of $0.5 \mathrm{~mm}$ used in the radiography centers for general shielding purposes were folded around the patient's testis regions (Figure 1). The superior edge of the shield was placed at the top of iliac crest and the inferior edge was approximately in the middle of the femur. The TLDs were positioned by a technician. Two groups of TLDs were applied during the chest scan to have a comparison and definition of the protection effect of the shield. To measure the dose values from testicular region, six TLD-100 chips were used for each patient. This was done in a way that three TLDs were attached to the top surface of the apron as an indicator of testes' surface doses without shielding, and three TLDs were positioned under the apron (at the same location) as an indicator of the doses with shielding (Figure 1; A and B). The TLDs 


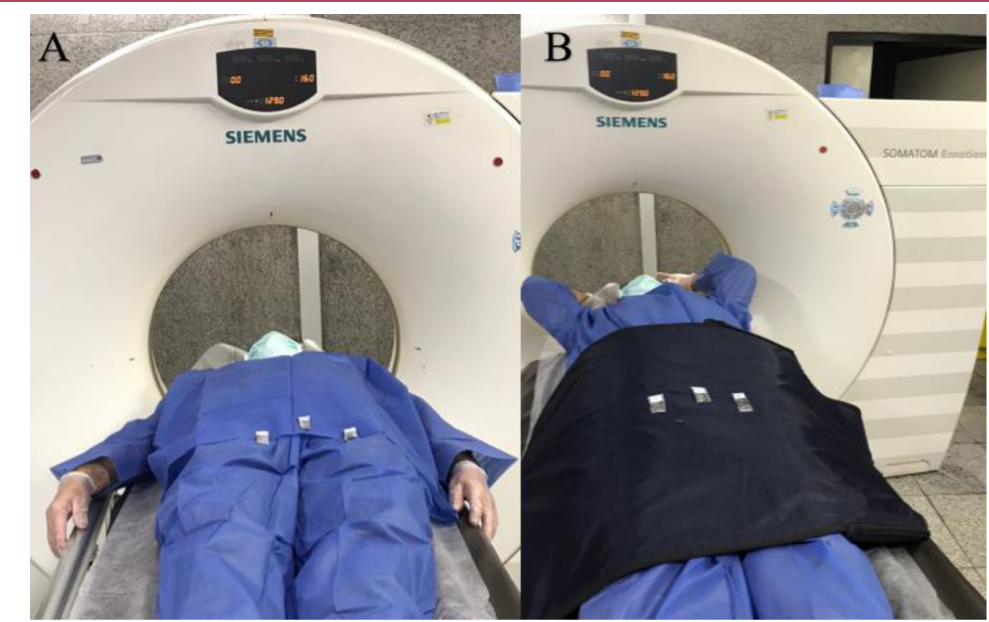

Figure 1: The locations of the thermoluminescent dosimeters (TLDs). Without lead apron (A) and with lead apron (B).

were embedded in plastic covers and glued to the desired points with leucoplast glue.

\section{Heritable risk estimation}

Regarding the "linear no threshold theory" [6], imaging with $\mathrm{CT}$ scanners, as medical devices using ionization radiation, can cause genetic and heritable side effects. The risk $\left(R_{T}\right)$ of genetic effects in future generations was obtained by multiplying the mean equivalent dose to the testes $\left(H_{T}\right)$ by the risk conversion factors $\left(f_{T}\right)$ obtained from New ICRP recommendations [18] as follows Equation 2:

$$
R_{T}=H_{T} / f_{T}
$$

\section{Statistical analysis}

Radiation doses to the testicles with and without the presence of the lead shielding were compared using the Wilcoxon test performed using SPSS software version 16 (IBM, USA). The level of statistical significance was set at $\mathrm{P}<0.05$.

\section{Results}

Patient compliance was very good and none of the patients exhibited pain during the shield positioning. Figure 2 illustrates the average and standard deviation ( \pm SD) of testicular doses with and without using the lead apron shielding. According to Figure 2, it is notable that there is a variation between the patients' doses. The results of the TLDs showed that the mean dose of the testicular region was 0.20 \pm 0.04 and $0.46 \pm 0.04 \mathrm{mGy}$, in the presence of the apron shield versus without using the shield, respectively. This demonstrates that using lead apron shielding reduced the radiation exposure of the testes by $56 \%$. Also, it is notable that the reduction was statistically significant $(p<0.001)$. Furthermore, in the current study, the heritable risk probability was obtained at $2.0 \times 10^{-5} \%$ and $4.6 \times 10^{-5} \%$ for the patients using the apron shield in comparison to without using it, respectively.

\section{Discussion}

The number of CT examinations has increased in the last decade, consequently, and the incidence of secondary cancer and heritable risks have been dramatically incremented [19]. Therefore, according to the ALARA (as low as reasonably achievable) principle, it is important that the patient exposure to radiation should be avoided unless it is deemed necessary [20,21].

Based on the National Radiological Protection Board (NRPB) recommendations, there is no such thing as a "harmless radiation dose" [8]. Since testes are accounted as one of the most sensitive organs, the use of shielding 


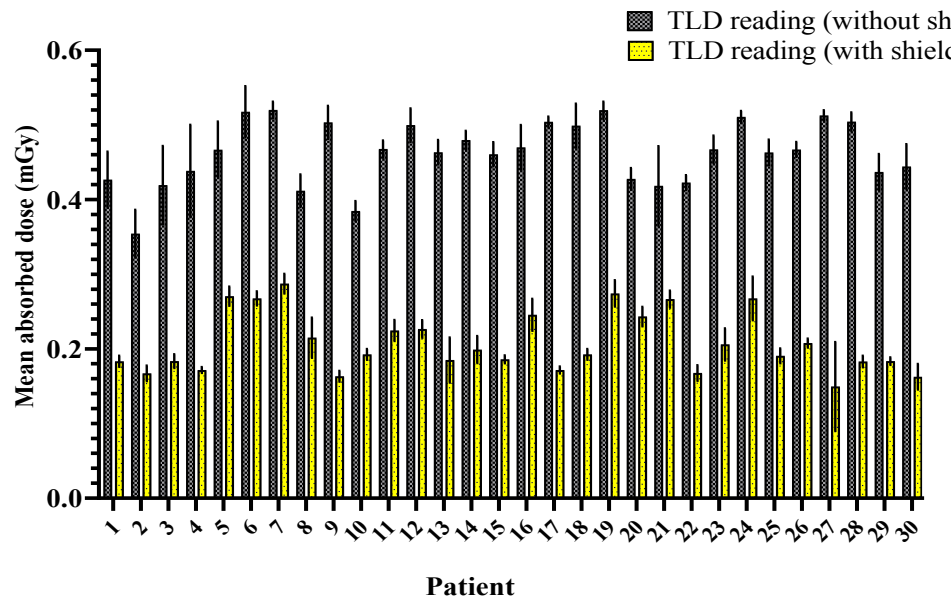

Figure 2: The mean surface dose $( \pm S D)$ at the testicular region with and without the lead apron.

techniques is recommended as far as possible in all interventional procedures $[10,12,16]$. Although there are various shields designed for gonadal dose reduction, these shields are not widely used in CT centers, due to their difficulty of use and accessibility in imaging centers. For this reason, we decided to use the common lead apron as a testicle shield positioned in the testis region during chest CT scans.

The leaf shields were used in CT scan procedures, mainly block anterior irradiations, however, lateral and posterior X-rays is not blocked by these shields. For this reason, we have folded the apron two times (thickness = $1 \mathrm{~mm} \mathrm{~Pb}$ ) in the lateral section of the patients to prevent higher laterally and posteriorly oriented radiation exposure.

Although in the current study, the BMIs for all patients were approximately the same, they can still affect the dose values. This is due to the fact that the absorption of scattered radiation would be higher in thick patients compared to thin patients, and this phenomenon can affect TLD readouts. The previous studies have reported that the body weight or BMI can change the gonadal dose values although it is not significant [12,22]. Furthermore, CT dose index (CTDI) and dose length product (DLP) can vary based on patient sizes, consequently, these are other factors which influence the re- sults [23]. We tried to reduce these factors by comparing the dose values in the presence and absence of the lead shielding for the same the patient.

In Table 2, we have summarized some exemplary studies that have investigated the various shields' effects on the testicular dose from CT scans in adult patients/phantoms. In Table 2, the results of the literature reports, including the type of study (patient or phantom), scanning protocol, testicular ranging dose $(\mathrm{mSv})$, and the percentage of dose reduction are depicted. According to Table 2, most of the previous studies have investigated the testicular dose using the phantom, except Hohl et al. [12] and Sancaktutar et al. [16] studies assessing the testicular dose on the patients at routine abdominopelvic MDCT examinations. But, in this study, we calculated the patients' testicular dose during the routine chest clinical MDCT examinations.

Our results showed that the lead apron shield can reduce the testicular dose significantly by $56 \%$. The dose reduction, type of study, CT scan, and shield have been expressed and compared with other related studies below.

Price et al. [24] have applied a wraparound protective device for shielding male Alderson phantom gonads. They reported that the doses to the gonads were reduced by $77-93 \%$ in the 
Table 2: Comparison of several studies reporting the details of computed tomography (CT) technique and dose reduction along with the current study method and results.

Testicular dose

(mSv)

\begin{tabular}{|c|c|c|c|c|c|c|}
\hline Study & Study Type & Scanning Protocol & Year & $\begin{array}{l}\text { Without } \\
\text { shielding }\end{array}$ & $\begin{array}{c}\text { With } \\
\text { shielding }\end{array}$ & $\begin{array}{l}\text { Reduction } \\
\text { (\%) }\end{array}$ \\
\hline $\begin{array}{l}\text { Present } \\
\text { study }\end{array}$ & $\begin{array}{l}\text { Patient study, } \\
\text { 0.5-mm apron } \\
\text { shield }\end{array}$ & $\begin{array}{l}\text { 16-slice spiral, } 16 \times 1.2-\mathrm{mm} \\
\text { collimation, } 80 \mathrm{mAseff}, 10 \mathrm{kV}\end{array}$ & 2020 & 0.09 & 0.04 & 56 \\
\hline $\begin{array}{l}\text { Price et } \\
\text { al. [24] }\end{array}$ & $\begin{array}{l}\text { Phantom study, } \\
\text { 1-mm wrap- } \\
\text { around apron }\end{array}$ & $\begin{array}{c}\text { Single-slice spiral, 10-mm } \\
\text { slice thickness, } 220 \mathrm{~mA}, 120 \\
\text { kV }\end{array}$ & 1999 & 0.82 & $0.19-0.05$ & $77-93$ \\
\hline $\begin{array}{l}\text { Hidajat } \\
\text { et al. } \\
\text { [25] }\end{array}$ & $\begin{array}{l}\text { Phantom study, } \\
\text { 1-mm testicular } \\
\text { capsule }\end{array}$ & $\begin{array}{c}\text { Single-slice sequential, } \\
\text { 10-mm slice thickness, } 250 \\
\text { mAs/slice, } 120 \mathrm{kV}\end{array}$ & 1996 & 1.46 & 0.07 & 95 \\
\hline $\begin{array}{l}\text { Hohl et } \\
\text { al. [12] }\end{array}$ & $\begin{array}{l}\text { Patient study, } \\
\text { 1-mm testicular } \\
\text { capsule }\end{array}$ & $\begin{array}{c}\text { 16-slice spiral, } 16 \times 1.5-\mathrm{mm} \\
\text { collimation, } 150 \mathrm{mAseff}, 120 \\
\mathrm{kV}\end{array}$ & 2005 & 2.40 & 0.32 & 87 \\
\hline $\begin{array}{l}\text { Grobe et } \\
\text { al. [22] }\end{array}$ & $\begin{array}{l}\text { Patient study, } \\
\text { 1-mm wrap- } \\
\text { around circular }\end{array}$ & $\begin{array}{l}\text { 16-slice spiral, } 16 \text { × 1.5-mm } \\
\text { collimation, } 150 \mathrm{mAs}, 120 \mathrm{kV}\end{array}$ & 2009 & 19.2 & 0.7 & 96 \\
\hline $\begin{array}{l}\text { lball et } \\
\text { al. [10] }\end{array}$ & $\begin{array}{l}\text { Phantom study, } \\
\text { shield designed } \\
\text { and 0.7-mm lead }\end{array}$ & $\begin{array}{c}\text { 64-slice spiral, } 64 \text { × 0.6-mm, } \\
150 \text { mAseff, } 120 \text { kV }\end{array}$ & 2011 & 0.018 & 0.001 & 93 \\
\hline $\begin{array}{l}\text { Sancak- } \\
\text { tutar et } \\
\text { al. [16] }\end{array}$ & $\begin{array}{l}\text { Patient study, } \\
\text { 0.7-mm wrap- } \\
\text { around circular }\end{array}$ & $\begin{array}{c}\text { 64-slice spiral, } 16 \times 1.25-\mathrm{mm} \\
\text { collimation, } 250 \text { mAseff, } 120 \\
\mathrm{kV}\end{array}$ & 2012 & 69 & 6.8 & 90.2 \\
\hline
\end{tabular}

presence of the shield during abdominal and pelvic CT examinations. In another study, Hidajat et al. [25] used a Alderson-Rando phantom, and they obtained a $95 \%$ reduction dose using a $1 \mathrm{~mm}$ lead testicular capsule during the whole abdomen CT scan.

The dose reduction for testis was $96 \%$ in Grobe et al. [22] study during the abdomen/ upper pelvis CT scan, which is the highest dose reduction among the other studies expressed in Table 2. In their study, 51 male patients participated and used a $1 \mathrm{~mm}$ lead equivalent of the testicle shield (made of sin- gle-ply lead rubber). Hohl et al. [12] estimated the testicular dose on the patients during routine abdominopelvic CT scans and used $1 \mathrm{~mm}$ lead capsule shields. They found that the dose decreased by $87 \%$ to the gonads in the presence of the shield. Testicular dose reduction was $90.2 \%$ in Sancaktutar et al. [16] study. In their study, the dose decreased from 69 to 6.8 $\mathrm{mSv}$ when 8 fluoroscopy radiation-protection gloves $(0.35 \mathrm{~mm}$ lead equivalent $)$ were used during abdominopelvic CT scan on the patients.

A study by Iball et al. [10] is closely similar 
to our research. They investigated the testicular dose reduction when they used lead apron as abdominopelvic shielding during chest CT examination. However, they used a RANDO phantom for scanning procedures. The maximum dose reduction was obtained at $93 \%$.

The main reasons for the differences in dose reduction values in the previous studies can be related to different shielding types, the region of imaging, CT parameters, and machine types.

The exposure to ionizing radiation during medical imaging procedures may generate biological effects such as cell death, degradation of DNA, and tumorigenesis [26]. Consequently, these effects can increase the individual's lifetime risk of developing cancer or a hereditary effect in future generations [27]. In the ICRP reports in 2008 (New ICRP recommendations) [18], the heritable risks are the major random radiation damage considered for testicles in low dose irradiations. Therefore, in the current research, we evaluated the heritable risks induced by chest CT scans with or without using the lead apron shielding. According to the results, although this risk was very low without lead apron, the heritable risks was reduced significantly in the presence of the apron on the testis regions. According to the following statement from ICRP recommendation [27]: patient radiation doses must be maintained at a minimum value to ensure maximum patient protection. Therefore, it seems that decreasing the dose and heritable risk as much as possible are important during the medical ionization radiation procedures.

We did not investigate the radiation dose in pediatric testicular regions, and women gonadal surface dose using common lead apron shielding. Therefore, for future research, it is suggested that the lead apron shield should be used for a large number of children and women, and dose reduction be compared with adult patients as well. In addition, dose reduction in other organs like kidney and liver can be assessed for further examination of the lead apron usage.

\section{Conclusion}

In this study, the researchers focused on reducing the testicular region dose using the lead gown, used as a common apron in radiology centers. The results demonstrated that the dose in testicular region decreased significantly during the chest MDCT scan when the shield was used. It is notable that this decrease was 56\% (2.3 times). Therefore, we recommend routine use of lead apron shield as an appropriate gonadal shield in male patients undergoing chest MDCT examinations.

\section{Acknowledgment}

This article was extracted from a master's thesis in Radiobiology and Radiation Protection by the first author and it was supported by Babol University of Medical Sciences (Babol, Iran). The authors would like to thank the radiography center of Rouhani Hospital for their collaboration in this project.

\section{Conflict of Interest}

None

\section{References}

1. Valentin J. Managing patient dose in multi-detector computed tomography (MDCT). ICRP Publication 102. Ann ICRP. 2007;1-8. doi: 10.1016/j. icrp.2007.09.001. PubMed PMID: 18069128.

2. Hart D, Wall BF, Hillier MC, Shrimpton PC. Frequency and collective dose for medical and dental X-ray examinations in the UK, 2008. HPA-CRCE-012; UK: HPA; 2010.

3. Davoudi M, Khoramian D, Abedi-Firouzjah R, Ataei G. STRATEGY OF COMPUTED TOMOGRAPHY IMAGE OPTIMISATION IN CERVICAL VERTEBRAE AND NECK SOFT TISSUE IN EMERGENCY PATIENTS. Radiat Prot Dosimetry. 2019;187(1):98-102. doi: 10.1093/rpd/ncz145. PubMed PMID: 31135908.

4. Khoramian D, Sistani S, Firouzjah RA. Assessment and comparison of radiation dose and image quality in multi-detector CT scanners in non-contrast head and neck examinations. Pol J Radiol. 2019;84(3):617. doi: 10.5114/pjr.2019.82743. PubMed PMID: 31019596. PubMed PMCID: PMC6479057.

5. Turner AC, Zankl M, DeMarco JJ, et al. The feasibility of a scanner-independent technique to esti- 
mate organ dose from MDCT scans: Using to account for differences between scanners. Med Phys. 2010;37(4):1816-25. doi: 10.1118/1.3368596. PubMed PMID: 20443504. PubMed PMCID: PMC2861967.

6. Cohen BL. A test of the linear-no threshold theory of radiation carcinogenesis. Environ Res. 1990;53(2):193220. doi: 10.1016/s0013-9351(05)80119-7. PubMed PMID: 2253600.

7. Khorramian D, Sistani S, Banaei A, Bijari S. Estimation and assessment of the effective doses for radiosensitive organs in women undergoing chest CT scans with or without automatic exposure control system. Tehran Univ Med J. 2017;75(7):496-503.

8. Hart D, Hillier MC, Wall BF. Doses to patients from medical X-ray examinations in the UK-2000 review. NRPB report; UK: NRPB; 2002.

9. Edgar RG, Patel M, Bayliss S, et al. Treatment of lung disease in alpha-1 antitrypsin deficiency: a systematic review. Int J Chron Obstruct Pulmon Dis. 2017;12(1):1295-08. doi: 10.2147/COPD.S130440. PubMed PMID: 28496314. PubMed PMCID: PMC5422329.

10. Iball GR, Brettle DS. Organ and effective dose reduction in adult chest CT using abdominal lead shielding. Br J Radiol. 2011;84(1007):1020-26. doi: 10.1259/ bjr/53865832. PubMed PMID: 22011831. PubMed PMCID: PMC3473701.

11. Protection R. The 2007 recommendations of the International Commission on Radiological Protection. ICRP publication 103. Ann ICRP. 2007;37(2-4):1332. doi: 10.1016/j.icrp.2007.10.003. PubMed PMID: 18082557.

12. Hohl C, Mahnken AH, Klotz E, Das M, et al. Radiation dose reduction to the male gonads during MDCT: the effectiveness of a lead shield. $A m$ J Roentgenol. 2005;184(1):128-30. doi: 10.2214/ ajr.184.1.01840128. PubMed PMID: 15615962.

13. Shielding B. Assessing the image quality and eye lens dose reduction using bismuth shielding in computed tomography of brain. J Kerman Univ Med Sci. 2018;25(6):471-82

14. Dauer LT, Casciotta KA, Erdi YE, Rothenberg LN. Radiation dose reduction at a price: the effectiveness of a male gonadal shield during helical CT scans. BMC Med Imaging. 2007;7(5):1-7. doi: 10.1186/14712342-7-5. PubMed PMID: 17367529. PubMed PMCID: PMC1831769.

15. Daniels C, Furey E. The effectiveness of surface lead shielding of gonads outside the primary X-ray beam. J Med Imaging Radiat Sci. 2008;39(4):18991. doi: 10.1016/j.jmir.2008.09.001. PubMed PMID: 31051779.

16. Sancaktutar AA, Bozkurt $Y$, Önder $H$, et al. A new practical model of testes shield: the effectiveness during abdominopelvic computed tomography. J Androl. 2012;33(5):984-89. doi: 10.2164/jandrol.111.015560. PubMed PMID: 22207708.

17. Groves AM, Owen KE, Courtney HM, et al. 16-detector multislice CT: dosimetry estimation by TLD measurement compared with Monte Carlo simulation. Br J Radiol. 2004;77(920):662-65. doi: 10.1259/ bjr/48307881. PubMed PMID: 15326044.

18. Wrixon AD. New ICRP recommendations. J Radiol Prot. 2008;28(2):161. doi: 10.1088/0952-4746/28/2/ R02. PubMed PMID: 18495983.

19. De González AB, Mahesh M, Kim K-P, et al. Projected cancer risks from computed tomographic scans performed in the United States in 2007. Arch Intern Med. 2009;169(22):2071-77. doi: 10.1001/ archinternmed.2009.440. PubMed PMID: 20008689. PubMed PMCID: PMC6276814.

20. Linton OW, Mettler Jr FA. National conference on dose reduction in $\mathrm{CT}$, with an emphasis on pediatric patients. Am J Roentgenol. 2003;181(2):321-29. doi: 10.2214/ajr.181.2.1810321. PubMed PMID: 12876005.

21. Slovis TL. The ALARA concept in pediatric CT: myth or reality? Radiology. 2002;223(1):5-6. doi: 10.1148/ radiol.2231012100. PubMed PMID: 11930041.

22. Grobe H, Sommer M, Koch A, Hietschold V, Henniger J, Abolmaali N. Dose reduction in computed tomography: the effect of eye and testicle shielding on radiation dose measured in patients with beryllium oxide-based optically stimulated luminescence dosimetry. Eur Radiol. 2009;19(5):1156-60. doi: 10.1007/ s00330-008-1241-1. PubMed PMID: 19082601.

23. Zarb F, Rainford L, McEntee MF. AP diameter shows the strongest correlation with CTDI and DLP in abdominal and chest CT. Radiat Prot Dosimetry. 2010;140(3):266-73. doi: 10.1093/rpd/ncq115. PubMed PMID: 20332128.

24. Price $R$, Halson $P$, Sampson M. Dose reduction during CT scanning in an anthropomorphic phantom by the use of a male gonad shield. Br J Radiol. 1999;72(857):489-94. doi: 10.1259/ bjr.72.857.10505015. PubMed PMID: 10505015.

25. Hidajat N, Schröder RJ, Vogl T, Schedel H, Felix R. The efficacy of lead shielding in patient dosage reduction in computed tomography. ROFO. 1996;165(5):46265. doi: 10.1055/s-2007-1015790. PubMed PMID: 8998318.

26. Shah DJ, Sachs RK, Wilson DJ. Radiation-induced cancer: a modern view. Br J Radiol. 2012;85(1020):116673. doi: 10.1259/bjr/25026140. PubMed PMID: 23175483. PubMed PMCID: PMC3611719.

27. ICRP. Radiological protection in medicine. ICRP Publication 105. Ann ICRP. 2007;37(6):1-64. 